\title{
Using Computer mediated Team based Learning for Developing EFL Prospective Teachers' Presentation Skills and reducing their Foreign Language Anxiety
}

\author{
Hasnaa Sabry Abdel-Hamid Ahmed Helwa
}

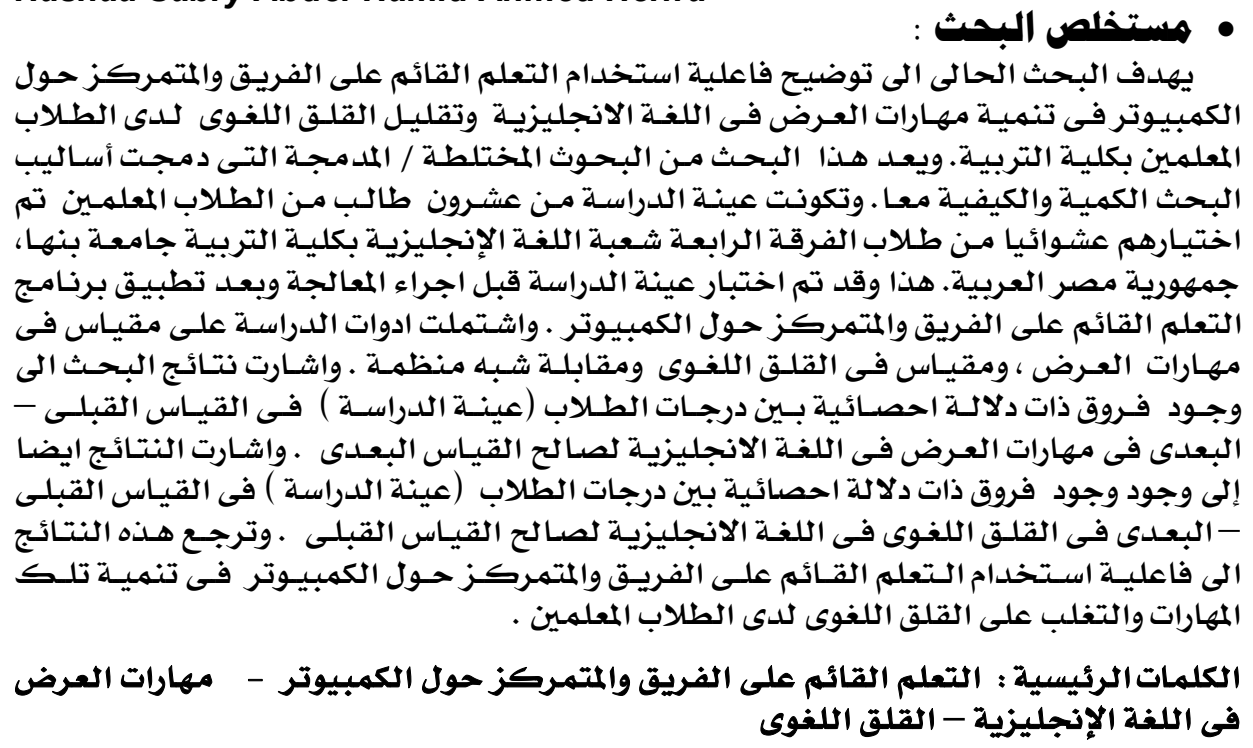

\section{Abstract :}

The aim of this research was to investigate the effectiveness of using computer mediated team based learning in developing EFL prospective teachers' presentation skills and reducing their foreign language anxiety. The design of the research is a mixed research methodology. It combines both quantitative and qualitative methods of inquiry. The study sample consisted of twenty students enrolled in fourth year English section at Faculty of Education, Benha University, Egypt. They were tested before and after the intervention. They were taught through a computer mediated team based learning. The instruments of the research included an EFL presentation skills scale, foreign language anxiety scale and a semi-structured interview. Results of the research revealed a statistically significant difference between the mean score of the study participants in the pre and post administration of the EFL presentation skills in favor of the post administration. Also, students' foreign language anxiety was reduced. These results were ascribed to computer mediated team based learning.

Keywords: - EFL Presentation Skills- Foreign Language AnxietyComputer Mediated Team based Learning.

\section{Introduction}

Most students studying English as a foreign language share a common problem with organizing and communicating their

\section{7}


thoughts and ideas orally. This may be due to the fact that learners do not benefit from sufficient practice and opportunities to speak in the classroom. Second, learning to speak is a complex process not readily known to the learners. Thus, learners are not familiar with the skills and strategies they can use to develop their speaking ability. Third, EFL learners have little opportunity to develop the skills for arranging their ideas cohesively and coherently while speaking. Finally, they are not familiar with the criteria by which their oral performances are assessed such as; self-efficacy, level of presentation skills and perception of the learning process with special focus on the perceived difficulty to assess their peers (Mazdayasna, 2012).

Teaching presentations skills in English gives students the opportunity to participate in a student centered classroom while at the same time developing individual presentation skills such as speech writing, public speaking, and computer literacy through different activities. These activities are designed to give students as many opportunities to use English as possible. The teacher's main role is to introduce and explain new concepts and direct activities (MacAnthony and Mccrohan, 2000).

Thus, it can be said that teaching presentation skills is one of many options exemplifying a meaningful task-based activity. It should be clear that conceiving, preparing and performing presentations is a synthesis of different skills and knowledge areas, such as (vocabulary, discussion, note taking, confidence building, fluency, and body language). This cycle of tasks requires much planning over several classes, engaging students in an extended process of learning. Thus, Otoshi and Heffernan (2008) indicated that learners identified the following as important when making oral presentations: clarity of speech and voice quality, correctness of language, and interaction with the audience. It can be said that oral presentation evaluation criteria consist of multiple factors including; language use, content, delivery, and effectiveness of visual aids.

Students receive instruction on how to prepare and deliver presentations in English, and practice their presentation skills in

\section{8}


pairs and/or groups before presenting in front of the class. Instruction and practice focus on three aspects of presentations: the verbal message (pronunciation, intonation), the non-verbal message (eye contact, posture, gestures, visual aids) and the rhetorical message such as speech building strategies (organization, logic, support). Non-verbal and verbal aspects of a presentation are taught as a series of skills and once these skills are introduced, students practice them through pair and group work. Students are guided through the process as they prepare their presentations, and have ample opportunity to practice with partners before each performance (MacAnthony and Mccrohan, 2000). As a result, King (2002) clarified that there are many advantages of presentations such as : bridging the gap between language study and language use; using the four language skills in a naturally integrated way; helping students to collect, inquire, organize and construct information; enhancing team work and helping students become active and autonomous learners.

In addition, most poor presenting is the result of bad habits such as not looking at the audience or muttering instead of speaking clearly. Yet most people are quite capable of making eye contact and speaking clearly; they may not even realize that they do not do these things, and it can come as quite a shock if they see a video of their performance. If they then take one aspect of their presentation, such as their poor pronunciation, and work at improving it, they will find that not only will their words soon become clearer but they will also start to speak more clearly as a matter of habit, without having to think about it at all. They can then take the next feature they want to improve and work at setting up another good habit. In this way, they will become better presenters as well as gain more confidence (Emden and Becker, 2004).

Students hesitate to prepare presentations at the beginning of the course. They often come to the presentations without adequate practices, which lead to poor performances as a natural result. This is not from their laziness or lack of capabilities to handle the tasks. Once they receive enough feedback and know

\section{9}


how to improve their presentations, they find it much easier to work on their presentations. Realizing students' attitude towards presentations, presentation practice is scheduled one week before the actual presentations. The practice significantly improves the students' presentations. The students are asked to practice their presentations in groups at least two times prior to the practice sessions (Suwa, Miyahara and Ishimatsu,2012, Toth, 2007).

It is widely believed that learning a foreign language can be a stressful activity for some learners. Therefore, there is a negative relationship between foreign language anxiety (FLA) and the level of achievement. FLA has been described by employing different categorizations. Two of the most wellknown classifications are trait-state and facilitating-debilitating views of anxiety. The former states that trait anxiety is stable over time, while state anxiety is a transient and moment-tomoment feeling. The latter proposes that anxiety does not necessarily impede learning, and in some cases it could improve language performance and have a positive effect on language leaning. In other words, while debilitating anxiety has negative impact on learners' performance, facilitating anxiety can actually enhance it. State anxiety has been defined as it consisted of subjective feelings of tension, apprehension, nervousness and worry, with associated arousal of the autonomic nervous system. Trait anxiety has been defined as stable individual differences in anxiety proneness in situations perceived as dangerous and threatening. FLA is a distinct complex of selfperceptions, beliefs, feelings, and behaviors related to classroom language learning arising from the uniqueness of the language learning process (Al-Shboul1, et.al.,2013,Cui, 2011, Khodadady and Khajavy, 2013).

Students' anxiety of presentation exists when the student puts himself/ herself on the spot when he/ she presents. The audience will be judging, not just his/ her ideas and evidence, but he/she as well. People may not remember reports or spreadsheets easily, but a presentation can make a powerful impression that lasts. If the presenter seemed nervous, incompetent or ill-informed, that

\section{0}


reputation will stick at least until the next presentation. Thus, the effective presenter puts himself at center-stage. An ineffective presenter tries to hide behind notes, slides or computer-generated graphics. To become more effective, the presenter needs to take control of the three core elements of the event: the material; the audience; and himself/ herself (Arnaiz and Guillén, 2012, Barker,2010, Occhipinti , 2009, Zheng,2008).

FLA is common among foreign language learners and it is seen as one of the great obstacles of FL learning and achievement. Therefore, lower achievement with higher anxiety is attributed to negative effects of anxiety on language learning. When teachers are more aware of language anxiety, they will be more prepared in conducting language activities in the classroom and more sensitive when dealing with their students. Besides, they can identify ways to create an environment which is conducive for foreign language learning. They would be aware of such socio-psychological constraints like thoughts of failure, deprecating thoughts, or low selfesteem. Through this awareness, they can develop their social and personal well-beings in their future university life and working environment where English language is a vital skill to survive (Lian and Budin ,2014).

In classrooms, learners may feel cognitive tension when their expectations about the content and organization of a course are not met, and affective tension when there is unsatisfactory interaction with other learners or the instructor. FLA has been attributed to the inability to present one's ideas and opinions as much as one can in the target language, which can undermine self-esteem and threaten one's self-image. In addition, the inability to pronounce words correctly or use correct grammar can lead to negative evaluation by others, and the inability to comprehend spoken and written input, including instructions, can lead to confusion and embarrassment about how to respond or act (Akbari and Sadeghi ,2013, Andrade and Williams, 2009).

In addition, Abderrezzag (2009) and Williams and Andrade (2008) presented the variables related to FLA. These variables fall into two main categories: situational variables and learner 
variables. Situational variables include, for example, course level, course organization, course activities, instructor behavior and attitudes, and social interaction among learners. Learner variables include ability (both perceived and actual), age, attitudes, beliefs, culture, gender, learning styles, and personality variables among others. These independent variables interact in complex ways that create anxiety-provoking situations for many students. In addition to the multiple variables, another complexity of classroom anxiety is that it may occur during one or more stages in the learning process. These stages are input, processing (mental planning), and output.

Therefore, it can be said that presentation is an effective communicative activity that has been widely adopted by EFL teachers to promote oral proficiency. However, when oral presentations are assigned in class, the teacher will get either complete silence or grumbles from students who find the idea of oral presentations frustrating and intimidating. Students are overwhelmed with the research and communication skills that are necessary for a successful presentation. Some students who invest time and effort into an oral presentation do not always get the intended outcomes. Speech anxiety and limited presentation skills are the major problems that lead to learners' oral presentation failures. In order to help students effectively cope with their fear of oral presentations, it is essential for teachers to acknowledge that speech anxiety is perfectly normal. Having an open discussion on speech anxiety will assist students to feel that they are not alone (King ,2002).

The communicative approach to English teaching has been very popular in many EFL college conversation classes. Having students give oral presentations in front of the class is one of learner- centered activities that has been widely included in teachers' lesson plans to improve students' oral proficiency. Thus, students' presentation problems sometimes defeat the purpose of developing language skills .In addition, with the availability of technology both at school and home, student- made presentations with video cameras, slide projectors, PowerPoint and other visual aids could be much more exciting and interesting than traditional ones (King 2002). 
In a foreign language classroom, working in informal small groups, having pairs or small groups of learners write up dialogue, do exercises, and research a project together have been common practice. It is important to understand, however, the crucial difference between merely placing learners into small groups to work together on isolated activities and structuring a team-based collaborative learning environment. In the team-based environment, learners work with the same team for the entirety of a semester. The use of teams for language learning is aligned with Vygotsky's belief that all higher-order functions develop out of language-based social interaction and that collaborative learning is essential for traversing the "Zone of Proximal Development" (ZPD), that is, for bridging the gap between what learners can do alone versus what they can accomplish by collaborating with others. In other words, the effectiveness of team based learning $(T B L)$ as an instructional strategy is based on the fact that it nurtures the development of high levels of group cohesiveness which, in turn, results in a wide variety of other positive outcomes. It clearly takes a transformation process to evolve a small group into a powerful, cohesive learning team (Michaelsen and Sweet, 2008).

Therefore, teachers who try to shift from traditional forms of teaching to a team learning approach will find that requires three important changes. First, the primary learning objectives of the course will shift. Instead of being primarily focused on familiarizing students with key concepts, the course goals will also include ensuring that students learn how to use those concepts. Second, the role and function of the teacher will also change. Instead of just being someone who dispenses information and concepts, the teacher will need to design and manage the overall instructional process. Third, there will also be a change in the role and function of students in the course. Instead of being passive recipients of information and content, students will need to be responsible for the initial acquisition of the content and for working collaboratively with other students to learn how to use the content (Michaelsen, 2008).

TBL is an instructional strategy involving multiple small groups in which learners must actively participate. The instructor acts as both facilitator and content expert as necessary. It originally

\section{3}


developed to promote active learning in large college undergraduate classes. It is a fairly new approach to teaching in which students rely on each other for their own learning and are held accountable for coming to class prepared. In TBL, learners work within the same team for the entirety of the semester. The rationale for this format is that it takes time for group members to get to know each other well enough to start functioning effectively as a team. Ideally, TBL proponents recommend groups of 5-7 learners in order to ensure that the team will have ample resource. Teams are formed and activities are designed according to several guidelines. First, teams must be properly balanced with regard to such features as age, race, gender, as well as academic assets and abilities. Second, procedures that ensure both individual and group accountability must be in place. Third, group assignments must require input from all group members. Finally, learners must have the opportunity to evaluate their peers (LeMond, 2004).

Therefore, changes of this learning do not just happen automatically. They happen when the teacher is able to implement the four essential principles of TBL. The essential principles are: 1) groups must be properly formed and managed, 2) students must be made accountable for their individual and group work, 3) group assignments must promote both learning and team development, and 4) students must have frequent and timely feedback. TBL assumes that learning goals should be teacher-directed and used to guide individual and group learning activities. It uses a sequence of events that prompt students to engage in their initial exposure to the content before class, and then spend the majority of class time working on assignments in which they learn how to apply the knowledge (Michaelsen, 2008, Michaelsen and Sweet, 2008).

TBL is a structured form of small-group learning that emphasizes student preparation out of class and application of knowledge in class. Students are organized strategically into diverse teams of 5-7 students that work together throughout the class. Before each unit or module of the course, students prepare

\section{4}


by reading prior to class. Therefore, in comparison to groups involved in informal small-group work and collaborative learning, a team is characterized by a high level of individual commitment to the welfare of the team in addition to a high level of trust among team members. In order to develop an effective learning team, members spend time in databases and the worldwide web, and interact both synchronously in a chat discussion and asynchronously via email and discussion interacting together, pooling resources in order to meet common goals and complete challenging tasks (LeMond, 2004).

Thus, Emden and Becker ( 2004) and Partridge (2007) indicated that there are benefits of using team learning in teaching such as the workload and the stress are shared ;students can use a range of abilities ; variety is built into the occasion, as the audience has different voices to listen to and students can show how good they are at teamwork. In TBL everyone is contributing to move forward in a clear direction. Everyone works to achieve common, and shared goals. They also work together, collaborating and co-operating, to enable them to make progress. A team combines the energy, motivation, experiences and expertise of individuals for a shared purpose so that the team achieves more than the sum of the talents of its individual members. In a team, its members can: have a sense of belonging; have a clear purpose and know what they have to achieve; feel supported by other team members; be respected and valued for their contribution and share and solve problems together.

According to this, TBL is an innovative form of collaborative learning. The aim of TBL is to create a motivational context in which students become accountable for their learning .It is designed as an active learning strategy that fosters individual and group accountability as small groups of students work together to answer questions and solve problems. It employs a structured three-phase sequence: preparation, during which learners study an advance assignment defined by faculty, readiness assurance, where learners demonstrate knowledge through individual and group readiness assurance tests (RAT) and application (Inuwa et al., 2012). 
Shokri (2010) indicated that TBL has three phases. The instructor allocates ample time for students to first discuss in group. They brainstorm a variety of ideas and select them based on consensus. After that, the learners must write mini proposals that explain the information about the project. At the final stage, the groups will present their projects to the language instructor and their classmates. Also, Partridge (2007) clarified that there are three central components of TBL: the task; what the team is charged to achieve, the individuals; the members of the team and the team itself; and the way it operates. When a team is first put together, its members are likely to want to find out about the purpose of the team and the role they are expected to play. Team members recognize the need to agree upon ground rules in order to operate as a team. The team's culture and customs, the way its members will operate and collaborate become established practice. Team members are still likely to disagree at this stage, but they tend to be more positive and able to work together. At the end ,the team is able to perform effectively, delivering the benefits team-work can bring. They have the confidence and commitment needed to work cooperatively towards their shared team goals. The emphasis is on achieving the team's goals.

Recently, the technological advances in network-based communication along with a shift toward a more social view of learning present special promise for foreign language learners. One of the particular interest among various forms of computermediated communication (CMC) is synchronous, real-time communication or chatting due to its resemblance to oral interaction. Network-based CMC allows learners to communicate and collaborate with one another on-line via written text. CMC chatting has been shown to be beneficial for language learning. Not only has this procedure been found to promote more language production than in face-to-face oral discussions, higher rates of participation, increased motivation, and positive attitudes (LeMond, 2004).

The use of an electronic learning space can greatly enhance TBL. A common difficulty in the implementation of TBL is that in order to do the work, all members of a team must be present. The

\section{6}


use of a technology-supported learning context alleviates this problem. Technology can be used to share files, search databases and the worldwide web, and interact both synchronously in a chat discussion and asynchronously via email and discussion boards with other learners (LeMond, 2004).

Social networking Websites, such as YouTube, Twitter, and Facebook, have become extremely popular among Internet users who wish to share their ideas, videos, and other activities online. The use of social media such as Facebook and Twitter has rapidly grown to become a popular and influential form of computer mediated communication. The rationale behind using Facebook and Twitter for teaching and learning purposes is that they provide a platform or a meeting point for students who can socially interact with their classmates as well as communicate about their learning in their very own non-threatening space. In addition to the traditional lectures and tutorials, the online discussion forum of the Facebook and Twitter site has a tremendous potential to enhance learning and teaching, in particular for the development of higher order learning skills, student-centered pedagogy, authentic learning and interactive learning communities. Therefore, there is a need to investigate how students perceive and assess the effectiveness of Facebook and Twitter in providing a pedagogically sound virtual learning environment that could enhance their learning experience (Chartrand, 2012, Rasiah, 2014).

The use of digital technology via Facebook and Twitter enhanced TBL outside the classroom, complementing face-toface lessons. Students were also exposed to several studentcentered learning mechanisms including poster presentations and expert forums in an effort to provide them with a more holistic learning experience. The students' learning experience and motivation was assessed through content analysis of their reflective portfolios and their Facebook and Twitter postings. Thus, TBL has a positive impact on the students' learning experience and motivation. Facebook was indeed perceived as an innovative and effective tool in a student-centered learning environment that enriched students' educational experiences, increasing the relevance of the subject matter and encouraging 
students to collaborate effectively with their peers and faculty. From the perspective of the educator, the use of Facebook in a team-based pedagogy setting significantly enhanced the teaching and learning process as it allowed the educator to tap into the digital learning styles of the students and provided innovative ways of involving and motivating students in the learning process (Rasiah, 2014).

Facebook is one of the most commonly used sites by people of all age groups, not only as a social network site, but also as an online team-based pedagogically sound learning platform that is fast becoming recognized in the education community. Facebook has many applications that support teaching and learning and it has been found to cultivate positive learning experiences as well as to enhance the rapport between the educators and their students. The main aim of an educator is to ensure student learning takes place. It the main platform used for conducting online discussions and preparation to aid students in successfully completing their continuous assessments, which took the form of an individual report as well as a group presentation (Rasiah, 2014).

Twitter is described as a social networking and a microblogging service that users like to use for short messages of 140 characters in length. It is an interesting method for students to keep in touch with each other as well as with the teacher. One possible lesson may start with a teacher telling a story to the learners. Then, the teacher instructs the students to continue the story. Another idea may be for the teacher to ask trivia questions, and the students attempt to answer them in class (Chartrand, 2012).

Twitter is a social network in which the members of a community share their current activity by answering the question "What are you doing?". This form of social interaction is called microblogging. Microblogging tools enable users to post short messages that are distributed within their community. Users can post messages from their mobile devices, a Web page, from Instant Messengers and desktop clients. The same channels are

\section{8}


used for receiving messages. Twitter seems to be a perfect tool to support learning English, especially in blended classrooms, for the following reasons. First, Twitter is easily accessible from almost everywhere, so the students can practice at any time by sending and receiving messages either on the computer or the mobile phone. They can also decide how much time they spend reading and writing these messages. This is an essential feature for busy students. Second, Twitter is suitable for any level of English because in writing the messages, the students can chose a topic and grammatical structure fitting their level. Third, the use of Twitter as an online learning community can help to integrate students in the community who could not attend classroom (Borau1 et al., 2009).

\section{Context of the problem}

In light of the researcher's experience in teaching at the university level, and the review of related studies (i.e. Andrade and Williams, 2009; Erkaya, 2011 \& Suwa, Miyahara and Ishimatsu, 2012) it could be noticed that students faced problems while speaking in front of others and this is considered the biggest cause of anxiety followed by worries about grammatical mistakes, pronunciation and being unable to talk spontaneously. They also had an uncomfortable feeling when expressing their ideas in front of others. They have a communication anxiety, that is the learners' fear of communicating with other people which might lead to difficulty in speaking in public, difficulty understanding others and making themselves understood, as well as being silent learners during the language learning process. They also worry about how others view them which may also include avoidance of evaluative situations and the expectations that others might evaluate them negatively. There are some factors that lead to FLA inside classroom such as learning tasks and activities, teachers' engagement and even peer pressure .These observations are consistent with Diyyab (2013)s' study that investigated the effectiveness of using a blended learning based program in developing EFL speaking skills and reducing anxiety among student teachers.

\section{9}


To document the problem, the researcher conducted a pilot study on thirty students from fourth year students enrolled in English section at Faculty of Education, Benha University, Egypt. The pilot study consisted of an EFL presentation skills scale, and Foreign Language Anxiety Scale. The results of the both scales revealed that, students are afraid of presenting their ideas in front of others. They are worried about the grammatical mistakes, pronunciation and being unable to talk spontaneously. They did not use gestures and body language while presentation. They also did not have enough confidence while talking. They feel inferior to their peers. Thus, they are anxious while presentation.

\section{Statement of the problem}

In spite the importance of EFL presentation skills, fourth students enrolled in English section at Benha Faculty of Education have difficulties in presenting their ideas. They also have high level of foreign language anxiety. The present research aims at examining the effectiveness of using computer mediated team based learning in developing EFL presentation skills and reducing foreign language anxiety among prospective teachers at Faculties of Education.

\section{Questions of the study}

1. What are the features of a program based on computer mediated team based learning in developing EFL presentation skills and reducing foreign language anxiety among prospective teachers at Faculties of Education?

2. How far is a program based on computer mediated team based learning effective in developing EFL presentation skills among prospective teachers at Faculties of Education?

3. How far is a program based on computer mediated team based learning effective in reducing foreign language anxiety among prospective teachers at Faculties of Education?

\section{Review of Related Studies}

EFL Presentation skills are becoming a more important part of language teaching, especially in the university environment.

\section{0}


These skills prepare students for teaching presentations that they will likely be expected to carry out after graduating and getting jobs .Therefore, several researchers conducted studies for developing presentation skills as follows:-

King (2002) investigated the effect of using communicative approach in preparing EFL learners for oral presentation skills. The participants of the study included 42 students. The instruments of the study included an EFL oral presentation test and a rubric for scoring it. The results of the study indicated that having students give oral presentations in front of the class is one of learner centered activities that has been included in teachers' lesson plans to improve students' oral proficiency . In addition, the study also confirmed that using oral presentations in EFL classroom provides a rewarding and stimulating experience both for teachers in developing facilitating skills and for students in training themselves to have confident presentations in public.

Otoshi and Heffernen (2008) explored the factors EFL learners consider to be important when making presentations. Three hundred and four undergraduate students were surveyed at a large private university in Japan. A 30-item questionnaire was used to discover what components are considered to be important to learners in doing effective English presentations. Descriptive statistics and principal component analysis were used to analyze the results of the data. The results indicated that the participants considered the following three factors as the major criteria for effective English oral presentations: clarity of speech and voice quality; correctness of language; and interaction with the audience.

Greza and Berings (2010) investigated the reliability and validity of peer assessments of oral presentation skills. The sample of the study consisted of 95 students at university level. The instruments of the study consisted of presentation skills test and a rubric to score it. Results revealed that feedback and assessment play an important role in teaching and learning. Peer assessment is presented as an additional alternative to strengthen the central role of assessment. In addition, the results indicated

\section{1}


that learners with a positive self-efficacy are more likely to work harder, are more persistent, and attain higher achievement levels. Thus, they expected a positive correlation between self-efficacy and presentation performance. The good presenters know the criteria of a good presentation better than weaker presenters, and that good oral presentation performers are also better assessors.

Erkaya (2011) used an oral communication skills course to teach students how to communicate in English fluently. The participants of the study included undergraduate EFL students in Turkey. The instruments of the study consisted of an EFL presentation skills scale. The results of the study indicated that the course is not complete, however, until instructors teach students oral presentation skills. Oral presentation skills are an extension of oral communication skills: The former deals with planned usage of language; and the latter, mostly with unplanned usage of language. Once students have acquired some fluency in oral communication skills, they can learn oral presentation skills.

Csikosovaa, Senova, and Culkova (2012) investigated the effect of using e-learning on improving of communication and presentation skills of the university students. Results of the study clarified that living in information society, in which internet has become necessary media that is need for the work, education, information and contacts is very important. The participants of the study included thirty five students at university in Slovakia. The instruments of the study were presentation test and scale. The results also show the necessity of communication and humanization during education process through e-learning activities .Using e-learning activities helps students at university level in presenting their ideas confidently through adding animation, sounds, pictures of videos while the presentation process .

Ahangari, Rassekh-Alqol and Hamed (2013) examined the effect of peer assessment on oral presentation of Iranian English non-major students. The participants of the study consisted of 52 students of Azad and State universities of Tabriz and were divided into control and experimental groups. The peer assessment was

\section{2}


incorporated into the experimental group's course to explore whether and to what extent their oral presentation skills may enhance. Data were obtained through a Likert scale questionnaire of peer assessment. The results specified a statistically significant difference among the groups in oral presentation skills in favor of the experimental group. The results also suggested that, when assessment criteria are definitely established, peer assessment empowers students to evaluate the performance of their peers in a manner comparable to those of the teachers.

Based on the previous studies, university students should give presentations to their classmates and teachers. They should also focus on using the internet about how to successfully prepare for this task. Thus, good presentation skills will help students as they progress through their studies and, after graduation. Students become more confident enough while presenting their ideas through adding animation, sounds, pictures of videos while the presentation process.

In addition, anxiety as an important affective variable has been found to be correlated with English-learning achievement among different groups of people in various contexts. It has been observed that some students in English classrooms experience anxiety that results in stuttering and fast heart-beating. One of the important problems that cause students not to perform well in spoken English is language anxiety. Thus, there is a relationship between anxiety and English language learning which demonstrate the presence of foreign language anxiety among learners. Thus, several researchers conducted studies to overcome this anxiety as follows:-

Andrade and Williams (2009) conducted a study to present an overview of research devoted to foreign language learning anxiety and then examine in detail the reactions reported by Japanese university students to an anxiety-provoking situations in English-as-a-foreign language (EFL) classes. Questionnaire data was obtained from 243 Japanese learners in conversational English classes at 31 four-year universities in Japan. Overall, the findings indicated that some degree of

\section{3}


anxiety affected $75 \%$ of the learners and that the debilitating aspects of anxiety strongly hindered about $11 \%$ of them. Other findings included significant differences between male-female and high-low perceived ability groups on several dependent variables.

Awan et.al (2010) conducted a study to examine anxiety in English undergraduate classes with regard to the type of situations that provoke anxiety during different stages of the learning process and the relationship of anxiety to learners' achievement. Participants of the study include 149 undergraduates enrolled in second and sixth semester of different departments of University of Sargodha who are learning English as a foreign language. The questionnaire used in this study is the abbreviated form of Foreign Language Classroom Anxiety Scale (FLCAS). An inventory is also used to determine different situations that provoke anxiety. Finally, students' grades in English classes are taken to find its relationship with language anxiety. The results show that language anxiety and achievement are negatively related to each other. It is also found that female students are less anxious in learning English as a foreign language than male students. It is suggested that the classroom environment should be encouraging and motivating. Moreover, teachers need to deal with anxiety-provoking situations carefully.

Ay (2010) conducted a study to examine the foreign language anxiety of young adolescent students in relation to language skills at different levels. Data was collected from 160 Turkish participants who are learning English as a foreign language by the use of a modified version of the Foreign Language Classroom Anxiety Scale (FLCAS) . Results of this study revealed that the foreign language anxiety experienced by young adolescent students differed in relation to levels of instruction and to basic language skills. FLA is reported in receptive skills at beginner levels and then in productive skills as the advanced levels. Thus, it is suggested that students' level of instruction and the type of consequential anxieties they may experience in relation to skills should be taken into account when foreign language curricula and in-class activities are prepared.

\section{4}


Trang, Moni and Baldauf (2012) investigated anxious tertiary students' experiences in learning English as a foreign language $(E F L)$ in order to determine whether their anxiety affected their determination to study English. Participants were 49 non-English major students from a university in Vietnam who were identified as being anxious. Data were collected using autobiographies and interviews, and were analyzed using a content analysis approach. The findings indicated that awareness of the importance of English and volition were two important factors that influenced anxious students' determination to study English. The study suggested that students' awareness of the importance of English should be enhanced, and that their volitional strategies should be strengthened, in order to assist them in managing their anxiety effectively and thus to persist in EFL learning.

Diyyab (2013) investigated the effectiveness of using a blended learning based program in developing EFL speaking skills and reducing anxiety among student teachers. The design of the study was a pre-post, experimental group. The participants of the study were thirty second year, English section students at Sadat Faculty of Education, Minufiya University, Egypt. The instruments of the study were an EFL speaking test and English language Anxiety Scale. The results of the study revealed that the participants' EFL speaking skills were developed and their English language anxiety was reduced after the implementation of the blended learning based program.

Khodadady and Khajavy (2013) conducted a study to determine firstly the relationship between language anxiety and motivation among Iranian EFL learners. Secondly, a foreign language achievement model based on language learning anxiety and motivation was developed and tested by structural equation modeling. To achieve the purposes, foreign language classroom anxiety scale (FLCAS) and language learning orientations scale (LLOS) were administered to 264 participants. The results of the study showed that amotivation and less self-determined types of external motivation are positively related to language anxiety. Also, intrinsic motivation

\section{5}


and identified regulation were negatively related to language anxiety. The application of the structural equation modeling showed that both anxiety and motivation significantly predicted the English achievement of the language learners within an Iranian context.

Tsai (2013) conducted a study to investigate the relationship among foreign learning anxiety, foreign language test anxiety, and learning self-efficacy with regard to various genders and language proficiency levels. The participants in this study consisted of 256 freshmen in a senior high school in the middle of Taiwan. The data was gathered through questionnaires. The findings revealed significant differences among foreign learning anxiety, foreign language test anxiety, and learning self-efficacy with regard to various genders and language proficiency levels. Regardless of gender or language proficiency level, there was a positive correlation between foreign learning anxiety and foreign language test anxiety. On a contrary, there was a negative correlation between foreign learning anxiety and learning self-efficacy. Besides, there was a negative correlation between foreign language test anxiety and learning self-efficacy.

Therefore, it can be said that TBL is considered an instruction method in which students at various performance levels work together in small groups or teams toward a common goal. The students are responsible for one another's learning as well as their own. Thus, the success of one student helps other students to be successful. As a result several researchers investigated the effectiveness of TBL in foreign language teaching and learning as follows:-

LeMond (2004) investigated the use of team-based computermediated communication (CMC) in foreign language learning. The study also analyzed the quantity of speech and the quantity and type of speech actions produced by the learners .The sample of the study consisted of 38 university Spanish learners enrolled in third-semester beginning Spanish, because learners at this level generally have been exposed to enough grammar to be able to

\section{6}


communicate in the target language. Learners were divided into teams. The same teams worked together throughout the semester to complete online and in-class assignments. They were encouraged to use the Blackboard's functions to prepare for all assignments, and all Blackboard communication was required to be in Spanish. A total of nine teams participated in the study. Ideally, team-based learning proponents recommend groups of 5 to7 learners in order to ensure that the team will have ample resources. The instruments of the study included survey, interview and speaking test. The results of the study clarified that synchronous computer-mediated team based learning can increase the level of participation. It also found that learners produce more language, submit more turns at talk, and participate at higher levels in electronic conferencing sessions than in faceto-face discussions.

Reid-Hector (2006) examined the role of inquiry-based learning practices on team learning (TL) process; and mechanisms constructed to share or transfer learning to other teams within a larger action research. The participants consisted of 18 learners divided into teams. The team's learning coach was selected as one of the elite interviewees because this team member had expertise in the area of team and organizational learning. Data was systematically collected from in-depth interviews, document review, field notes from interviews, participant observation notes, review of documents / materials, and the Team Learning Survey (TLS). Results of the study clarified that inquiry-based learning practices (IBLP) facilitated experienced-based adult learning at the individual, team and organizational level. Also team learning was facilitated through use of IBLP, and mechanisms were created to transfer learning to other teams in the organization.

Abidin and Saleh (2010) conducted a study to present some qualitative findings of the soft skills that participants acquire through the process of learning. Two hundred and forty two undergraduates were involved in the study and were randomly grouped into 51 teams to develop team-based Learning Portfolio.

\section{7}


In the process of developing the portfolio electronically, each team strategizes collectively in conformance to the criteria explicitly transcribed on the course e-learning portal. Objectively, it provides participants the opportunity to exercise their soft skills while exploring their applications in the real world and new skills in using Power Point Presentation Skills. The data was obtained from the questionnaire, written evaluation and reflections of learning, the rating, verbal and non-verbal communication during the interviews. The soft skills that participants have demonstrated included leadership, managerial, communication, teamwork, writing, critical thinking, decision making and presentation. The results of the study clarified that team learning was highly acceptable among the sample of the study. They mentioned having fun doing the course, and were satisfied with the way the course was delivered and the materials used. The abilities of gathering information from all team members, organizing, coordinating, arranging and presenting all input on the compact disc and delivering it on time certainly demonstrated their soft skills.

Shokri (2010) conducted a descriptive study to explore whether team project activity can promote the frequent use of English language, practice learners' strategies, and promote learners' selfconfidence. He focused on how team project assignment helps students in developing their language skills and also cultivated essential soft skills. This study adopted a quantitative method by obtaining students' feedback through administering a questionnaire. There were 60 participants selected to respond to the questionnaire. The results of the study revealed that students' speaking ability improved through using team learning. Therefore, they can present their ideas and discuss it confidently. It revealed also that the students had positive attitude and judgments towards the use of team project as a teaching technique in classroom.

Rasiah (2014) conducted a study to assess the effectiveness of social media to enhance teaching and learning in a team-based learning environment involving large classes. The use of digital technology via Facebook enhanced team-based learning outside

\section{8}


the classroom, complementing face-to-face lessons. Students were also exposed to several student-centered learning mechanisms including poster presentations and expert forums in an effort to provide them with a more holistic learning experience. The students' learning experience and motivation was assessed through content analysis of their reflective portfolios and their Facebook postings. The results clearly showed the positive impact that team-based strategy had on the students' learning experience and motivation. Facebook was indeed perceived as an innovative and effective tool in a student-centered learning environment that enriched students' educational experiences, increasing the relevance of the subject matter and encouraging students to collaborate effectively with their peers . Also, the use of Facebook in a team-based pedagogy setting significantly enhanced the teaching and learning process as it allowed the educator to tap into the digital learning styles of the students and provided innovative ways of involving and motivating students in the learning process.

\section{Hypotheses of the Study}

Based on the related studies and research questions, the following hypotheses were formulated:

1. There is a statistically significant difference between the mean score of the study participants in EFL presentation skills on the pre-and post- administration of the EFL presentation skills scale in favor of the post- administration.

2. There is a statistically significant difference between the mean score of the study participants in EFL presentation sub-skills on the pre-and post- administration of the EFL presentation skills scale in favor of the post- administration.

3. There is a statistically significant difference between the mean score of the study participants in foreign language anxiety on the pre-and post- administration of the foreign language anxiety scale in favor of the pre-administration.

\section{9}




\section{Methodology}

1. A. Participants : Subjects of the present research consisted of 20 students. They were chosen randomly from fourth year students enrolled in English section at Faculty of Education, Benha University, Egypt. The participants represented one group which was taught through using team learning based on computer mediated communication.

2. B. Design : The present research is a partially mixed research methodology. It combines both quantitative and qualitative methods of inquiry to help bridge the gap between quantitative and qualitative research. To conduct the quantitative analysis the pre- post experimental group design was used. The study sample was tested before and after conducting the experiment. In addition a qualitative analysis of the students' performance is provided.

3. C. Instruments : In order to fulfill the purposes of the study, the following instruments were designed.

1- EFL Presentation Skills Scale : The EFL presentation skills scale was prepared by the researcher to measure EFL presentation skills among fourth year students at Faculty of Education, Benha University, Egypt. It is a pre-post scale . The scale builds on five components of presentation skills. These skills are verbal presentation skills, nonverbal presentation skills, questioning skills, audiovisual skills, and summarizing skills. The students were informed about the rating scale against which their performances would be evaluated. Each student had the chance to make a number of presentations that were evaluated on a Likert type scale as follows;

- Is competent at performing the skill and requires no additional practice.

- Can perform this skill but requires additional practice .

- Cannot perform this skill and requires extensive practice. (See appendix 1).

\section{0}


2- Foreign Language Anxiety Scale : The researcher prepared the scale based on the foreign language classroom anxiety scale by Horwitz et al. (1986). The researcher made some modifications to facilitate the items to the students and the process of calculating the students' responses to the scale items. Therefore, the scale in the present study consisted of (20) items scored on a 5-point Likert (strongly agree, agree, neutral, strongly disagree and disagree). The items were developed from students self-reports who were concerned about their foreign language classes. The scale included the three types of anxiety; communication apprehension, test anxiety, and fear of negative evaluation (See appendix 2).

3- Semi-Structured Interview: The interview was constructed to examine the importance of the team learning program based on computer mediated communication among fourth year students enrolled in English section at Faculty of Education, Benha University, Egypt and its effectiveness in developing EFL presentation skills and reducing foreign language anxiety. The interview took the format of face to face semistructured interview. The researcher interviewed students one time at the beginning of the study, a second time in the middle, and a third time at the end of the study, to gain greater insight on their presentation skills development and reducing foreign language anxiety, throughout the twenty weeks. The researcher generally asked the students about their participation in the program. She used open ended questions to avoid responding with yes-no (See Appendix 3). Five students participated in the interview and their responses were video recorded. The interview lasted for one hour. At the beginning of the interview, the researcher greeted the students and asked them to give brief self-introduction as a way to set the goal for the interview. Then, she told them the purpose of the interview and their own roles. If students did not understand any question, she could simplify it or change it .At the end of the interview, the researcher thanked the students for their participation. 


\section{Determining the Validity of the Research Instruments}

The EFL presentation skills scale, and Foreign Language Anxiety scale were submitted to a jury member (see appendix 4), they were asked to determine the validity of the instruments in terms of clear instructions, items and its suitability for the students' level. They indicated that the scales instructions were clear and suitable for students' levels and background knowledge. Therefore, the scales were considered valid measures of presentation skills and foreign language anxiety (Face Validity).To ensure the content validity of the scales, they were developed in the light of a systematic and accurate review of literature and previous studies. This accurate and systematic review determined the general form of the scales, questions and methods of correction. Therefore, the content of the scales was representative of the skills that were intended to be measured. Thus, the scales were valid and having a content validity.

\section{Determining the Reliability of the Research Instruments}

The reliability of the instruments was measured by using the test-retest method. The instruments were administered to a group of fourth year students enrolled in English section at Faculty of Education, Benha University, Egypt. Then, they were administered to the same group again after two weeks. The Pearson correlation between the two administrations was $(0.88)$ at the 0.01 level. Therefore, the instruments were reliable.

\section{Computer Mediated Team based Learning Program}

For achieving the purpose of the research, the researcher designed a team learning program based on computer mediated communication. After assessing fourth year students' enrolled in English section at Faculty of Education, Benha University, Egypt presentation skills and foreign language anxiety, the study sample was required to attend computer mediated team based learning program (see appendix 5).

\section{Objectives of the Computer Mediated Team based Learning Program}

The program aimed at developing EFL presentation skills and reducing foreign language anxiety among fourth year students

\section{2}


enrolled in English section at Faculty of Education, Benha University, Egypt.

\section{Content of the Computer Mediated Team based Learning Program}

The topics chosen for the program were selected from books and studies enriched with topics that motivate students. They contained variety of topics, situations and discussions designed for developing presentation skills and reducing foreign language anxiety. They were suitable for the fourth year students' enrolled in English section at Faculty of Education, Benha University, Egypt levels such as Barker (2010), Mandel (2000), and Emden and Becker (2004).

\section{Computer Mediated Team based Learning Program Frame- work}

The treatment began on 9th November 2013 and continued through 11th May 2014. The researcher met the students for two hours per week for twenty weeks and also communicated with them via Facebook and Twitter. Weeks (1-2-3) were used for pretesting and weeks (18-19-20) were used for post testing. Each session was devoted to the following: introduction, objectives, procedures, the role of the researcher and student and finally the performance. During the instructional procedures, different sessions had different learning goals and different methods were applied.

The program was taught to the study sample by the researcher herself. It lasted twenty weeks with fourteen instructional sessions and each session lasted for two hours. At the beginning of the program, the researcher introduced to the students what they are going to do. First, she told them about the objectives of the program and what they are supposed to gain as a result of their participation in the program (Goal Setting). After that she told them about the importance of presentation skills and reducing foreign language anxiety. Then she began to introduce the concept of computer mediated team based learning and its importance for language learning and EFL presentation skills and foreign language anxiety.

\section{3}


Following the introduction of the program, the rest of the program were instructional sessions through which the EFL presentation skills and foreign language anxiety were introduced .At the beginning of each session the researcher told students the objectives of the session, the researcher's role, the student's role, the instructional materials that will be used, the activities they will perform and ways of evaluating their progress .At the end of the each session, the researcher gave students some activities related to what they had learned in order to be sure that they mastered the skills in each session (formative evaluation). At the end of the program, the researcher assessed the students' achievement after implementing the program using the EFL presentation skills scale and foreign language anxiety scale (summative evaluation).

\section{The procedures of the Program}

In order to implement the computer mediated team based learning, there are four stages as follows:

\section{Dividing Students into Teams}

The students were divided into five teams. In team-based learning proponents recommended groups of 5 to7 learners in order to ensure that the team will have ample resources. The same teams worked together throughout the semester to complete online and in-class assignments. They were encouraged to use Facebook and Twitter to prepare for all assignments.

\section{On-line Assignments}

1. Throughout the semester, the team members completed online assignments. All the discussions appeared in the team's Facebook group and twitter and were accessible to all team members. The on-line assignments were carefully designed so that team members could get to know each other and built levels of understanding, support, and trust before working together to complete team projects. Therefore, the first on-line assignment required members to introduce themselves and share personal information about interests, backgrounds, expertise, and course expectations through a posting on the team's Facebook group.

\section{4}


2. In the next on-line assignment learners were required to read all the introductions posted to the Facebook group post by their teammates and respond directly to at least two by posting a reply to the original message. After several assignments that encouraged the establishment of a good group dynamic and strong rapport within the teams, the assignments began to focus on tasks that the team members were required to complete together.

3. The rationale behind these assignments with respect to collaborative learning was to teach the learners how to work toward a common goal as a team. For example, the teams were required to do several readings utilizing a collaborative reading technique. First, the reading was divided among the team members. For each section, one team member was assigned the role of "Recorder" and a different team member was assigned the role of "Monitor."

4. The job of the Recorder was to read the section, summarize it and post a summary to the team post. The job of the Monitor was to read the same section as well as the Recorder's summary of that section. Then the Monitor would post a message to the Team Facebook group and Twitter either to confirm the accuracy of the Recorder's summary or to note any errors or omissions made by the Recorder. This collaborative reading method is intended to encourage positive interdependence and facilitate participation.

\section{Oral Presentations}

One of the most important group projects was an oral in-class cultural presentation. A topic was assigned to each team to be prepared and undertaken collaboratively. The purpose of the oral presentation was to promote team-member accountability and whole-group participation. Students began to present their ideas and information to their peers.

\section{On-line Chat Discussions}

1- The learners also met in the language lab on five occasions to participate in chat discussions with their teams. Learners

\section{5}


entered the lab, chose a computer, and logged on to one of the facility computers. They then logged in to their team's Facebook or twitter.Instructors and learners can hold synchronous discussions, question-and-answer sessions, and review Web-based materials. Due to the synchronous nature, multiple users must participate at the same time. Learners enter their comments in the text box and hit the "enter" or "return" key to submit them. After hitting the "enter" key, the learner's comments appear in the chat window next to the learner's name.

2- Learners can view all entries by their teammates either as they appear or they can .The chat sessions were of two types: (1) chats based on specific themes that required each team to reflect back on the discussion and construct a summary of the discussion together; and (2) chats that required no such postactivity reflection.

\section{Findings of the Study}

\section{A. Quantitative Analysis of the findings}

The findings of the present research are presented in the light of the hypotheses of the research using the Statistical Package for Social Sciences (SPSS). The findings are stated as follows:

\section{Findings of Hypothesis (1)}

The first hypothesis states "there is a statistically significant difference between the mean score of the study participants in EFL presentation skills on the pre-and post- administration of the EFL presentation skills scale in favor of the post- administration ". Table(1) presents the students' mean scores, standard deviations, $t$-value and level of significance of the pre and post assessment of the study sample in EFL presentation skills.

Table (1) shows that the study sample outperformed in the post administration of the overall presentation skills, where "t-value" is (41.935) which is significant at the (0.01) level .Thus, the first hypothesis was supported.

\section{6}


Table (1):" ${ }^{\prime \prime}$ test between the mean scores of the study sample in the post assessment of the EFL Presentation Skills

\begin{tabular}{|c|c|c|c|c|c|c|c|}
\hline Skill & Assessment & N & Mean & S.D & $\begin{array}{c}\text { T- } \\
\text { Value }\end{array}$ & D.F & Sig. \\
\hline $\begin{array}{c}\text { EFL } \\
\begin{array}{c}\text { Presentation } \\
\text { Skills }\end{array}\end{array}$ & Pre & 20 & 58.500 & 6.501 & 41.935 & 19 & 0.01 \\
\cline { 2 - 6 } & Post & 20 & 123.0500 & 3.872 & & \\
\hline
\end{tabular}

\section{Findings of Hypothesis (2)}

The second hypothesis states "there is a statistically significant difference between the mean score of the study participants in EFL presentation sub-skills on the pre-and post- administration of the EFL presentation skills scale in favor of the postadministration ". Table (2) presents the students' mean scores, standard deviations, $t$-value and level of significance of the pre and post assessment of the study sample in EFL presentation sub-skills (i.e. verbal presentation skills, nonverbal presentation skills, questioning skills, audiovisual skills, summarizing skills).

Table (2): " $t$ " test between the mean scores of the study sample in the post assessment of the EFL Presentation Sub-Skills

\begin{tabular}{|c|c|c|c|c|c|c|c|}
\hline Skills & Assessment & $\mathbf{N}$ & Mean & S.D & $\begin{array}{c}\text { T- } \\
\text { Value }\end{array}$ & D.F & Sig. \\
\hline \multirow{2}{*}{$\begin{array}{c}\text { Verbal } \\
\text { presentation } \\
\text { Skills } \\
\end{array}$} & Pre & 20 & 17.650 & 3.407 & \multirow{2}{*}{27.304} & \multirow{2}{*}{19} & \multirow{2}{*}{0.01} \\
\hline & Post & 20 & 40.050 & 2.064 & & & \\
\hline \multirow{2}{*}{$\begin{array}{l}\text { Nonverbal } \\
\text { presentation } \\
\text { Skills }\end{array}$} & Pre & 20 & 18.300 & 4.105 & \multirow[t]{2}{*}{25.530} & \multirow[t]{2}{*}{19} & \multirow[t]{2}{*}{0.01} \\
\hline & Post & 20 & 41.050 & 1.276 & & & \\
\hline \multirow{2}{*}{$\begin{array}{c}\text { Questioning } \\
\text { Skills }\end{array}$} & Pre & 20 & 8.500 & 1.878 & \multirow[b]{2}{*}{15.040} & \multirow[b]{2}{*}{19} & \multirow[b]{2}{*}{0.01} \\
\hline & Post & 20 & 19.150 & 2.434 & & & \\
\hline \multirow{2}{*}{$\begin{array}{c}\text { Audiovisual } \\
\text { Skills }\end{array}$} & Pre & 20 & 6.350 & 1.565 & \multirow[b]{2}{*}{18.898} & \multirow[b]{2}{*}{19} & \multirow[b]{2}{*}{0.01} \\
\hline & Post & 20 & 14.400 & 0.883 & & & \\
\hline \multirow{2}{*}{$\begin{array}{c}\text { Summarizing } \\
\text { Skills }\end{array}$} & Pre & 20 & 7.700 & 1.593 & \multirow[b]{2}{*}{21.114} & \multirow[b]{2}{*}{19} & \multirow[b]{2}{*}{0.01} \\
\hline & Post & 20 & 17.400 & 0.821 & & & \\
\hline
\end{tabular}

Thus, table (2) indicated that the study participants were much better in the post application than the pre administration in EFL presentation sub-skills where "t" value is (27.304) for EFL verbal presentation skills, (25.530) for nonverbal presentation skills,

\section{7}


(15.040) for questioning skills, (18.898) for audiovisual skills and (21.114) for summarizing skills which is significant at the level of significance. Therefore, the second hypothesis was confirmed.

\section{Findings of Hypothesis ( 3 )}

The third hypothesis states that there is a statistically significant difference between the mean score of the study participants in foreign language anxiety on the pre-and post- administration of the foreign language anxiety scale in favor of the preadministration. Table (3) presents the students' mean scores, standard deviations, $t$-value and level of significance of the pre and post assessment of the study sample in foreign language anxiety.

Table (3): " $t$ " test between the mean scores of the study sample in the post application of the Foreign Language Anxiety

\begin{tabular}{|c|c|c|c|c|c|c|c|}
\hline Item & Assessment & $\mathbf{N}$ & Mean & S.D & T-Value & D.F & Sig. \\
\hline $\begin{array}{c}\text { Foreign } \\
\text { Language } \\
\text { Anxiety }\end{array}$ & Pre & $\mathbf{2 0}$ & $\mathbf{9 3 . 9 0 0}$ & $\mathbf{6 . 8 9 7}$ & & & \\
\cline { 2 - 5 } & Post & $\mathbf{2 0}$ & $\mathbf{2 7 . 0 5 0 0}$ & $\mathbf{2 . 3 9 5}$ & $\mathbf{4 8 . 0 8 2}$ & $\mathbf{1 9}$ & $\mathbf{0 . 0 1}$ \\
\hline
\end{tabular}

Table (3) indicated that the mean score of the study sample on the pre application is higher than that of the post administration where " $t$ " value is (48.082) which is significant at the level of significance. Before implementing the program most of the students are anxious and avoided communication and speaking. They did not have enough vocabulary, grammar and organization. After the implementation, they became motivated and enjoyed speaking in front of others. Therefore, the third hypothesis was confirmed.

\section{B . Qualitative Analysis of the findings}

At the beginning of the program, the students were afraid of speaking and presenting their ideas in front of others and their speaking was full of grammar mistakes, pauses, pronunciation errors and their ideas were not organized. They did not use gestures or body language correctly. They also seemed to lack confidence and self-efficacy while presentation. After participating in computer mediated team based learning, students gained more

\section{8}


confidence and began to use the body language and gestures in a better way. They used eye contact while presentation and their pronunciation improved. They started to speak more clearly. In the interview data, five students had similar positive reaction towards using computer mediated team based learning. They clarified that in team based learning everyone is contributing to move forward in a clear direction. Everyone works to achieve common, shared goals. They also worked together, collaborating and co-operating, to enable them to make progress. They also felt supported with each other.

To understand how students perceived the importance of computer mediated team based learning in developing presentation skills and reducing foreign language anxiety, some interview questions were asked. An excerpt from the researcher's transcripts provided insight into the students' perception about the activities in computer mediated team based learning program.

Students (1): When we participated in computer mediated team based learning program, we felt confidence and the ability to achieve our goals. When a team was first put together, we as members likely wanted to find out the purpose of the team and the role we expected to play. We asked ourselves certain questions such as: What's our role? ; How do we fit in? ; What are we expected to achieve? ; What resources do we have? ; Can we do it? How should we communicate and work together? Then try to achieve the goal. Thus, participating in TBL was more motivating and interesting.

Student (2): TBL is very important for improving presentation skills and reducing foreign language anxiety. Before participating in TBL, I was anxious and nervous of presentation because I put myself on the spot when I presented. The audience would be judging, not just my ideas and evidence, but me as well. Now, we as member of team collaborate with each other to achieve the goal. Also, I become more confident enough and take control of the three core elements of the event: the material; the audience; and myself.

\section{9}


Student (3): I think that using Facebook as a form of TBL is very interesting for me. It helps me and my team members to socially interact with our classmates as well as communicate about learning in non-threatening atmosphere. Before participating in TBL, I fear from speaking in front of others and this considered the biggest cause of anxiety followed by worries about grammatical mistakes, pronunciation and being unable to talk spontaneously.

Student (4): The program was good practice to help us improving presentation skills and reducing foreign language anxiety. It included various activities and tasks.

Student (5): Twitter is very important for improving presentation skills and reducing foreign language anxiety. I enjoy it very much.

Therefore, through computer mediated team based learning, students received instruction on how to prepare and deliver presentations in English, and practice their presentation skills in pairs and/or groups before presenting in front of the class. Instruction and practice focused on three aspects of presentations: the verbal message (pronunciation, intonation), the non-verbal message (eye contact, posture, gestures, visual aids) and the rhetorical message such as speech building strategies (organization, logic, support). Non-verbal and verbal aspects of a presentation were taught as a series of skills and once these skills were introduced, students practiced them through pair and group work. Students were guided through the process as they prepared their presentations, and had ample opportunity to practice with a partner or partners before each performance.

\section{Discussion of the Results}

The primary purpose of this study was to develop EFL presentation skills and reduce foreign language anxiety among fourth year students enrolled in English section at Faculty of Education, Benha University, Egypt through using program based on computer mediated team based learning. The program included variety of tasks and activities for helping students to

\section{0}


enhance their EFL presentation skills and reducing their foreign language anxiety. The results of the study indicated that the program proved to be statistically and educationally significant in developing EFL presentation skills and reducing foreign language anxiety among fourth year students at faculty of education.

EFL presentation skills included sub-skills .Regarding clarity of speech and voice quality, it was noted that participants judged an effective presentation on the combination of clarity of the presenter's presentation and his or her voice. Thus, in the process of making evaluation rubrics, teachers should pay attention to this factor by incorporating examples of good presentations and by demonstrating a clear and understandable voice. It was also noted that some students, especially those in the lower levels of proficiency, confused the clarity of speech component with that of a person who simply just spoke with a loud voice. Therefore, teachers should explain how clarity of speech and voice quality have a positive impact on oral presentation. This serves to act as guidance for learners striving to become more effective presenters.

With respect to correctness of language, participants in this study tended to be tolerant of grammatical errors during oral presentations. Therefore, it was considered important for the preparation stages of oral presentations, and could be dealt with teachers in class by clearly explaining the implications of these criteria to their learners, so they used this into their evaluations. Further, when preparing to assess their peers, learners should be made aware of the significance of the correctness of language criteria. Thus, learners prepared transcripts of their presentations, which could be checked by their peers. The presenter's peers focused on grammatical accuracy and vocabulary use. This ensured that a complete understanding is obtained by both presenters and their peers.

Interaction with the audience refers to the physical attention the presenter gives to the audience. This physical attention involved eye-contact, body language and paying attention to the audience's response to the presentation. It could be a difficult task

\section{1}


to judge exactly how much eye-contact and body language is sufficient in oral presentations. Teachers could demonstrate and stress the importance of presenter-audience interaction, and learners prepared for evaluating their peers' interaction with the audience with adequate training. This could be done by teachers and students in class: by giving both good and bad examples of presenter-audience interaction.

According to foreign language anxiety, the students were facing fear and anxiety in communicating with people. Difficulty in speaking in public, listening or learning a spoken utterance was all manifestations of communication apprehension. This type of anxiety in learning a foreign language derived from the learners' personalknowledge that they had difficulty understanding others and making themselves understood. Learners suffered from communication apprehension, they chose to keep silent in their English classes. Also, in fear of negative evaluations, the students faced problems like nervousness when questioned, they were embarrassed to volunteer answers, and felt that other students spoke better English. They were upset when they could not understand what the teacher corrected and often feared being laughed at by their peers. Generally they felt they were being judged by teacher and peers. Thus, participating in computer mediated team based learning helped the students to be more confident to present ideas and speak in front of others. They had high levels of self-efficacy and autonomy.

\section{Conclusions}

The results of the study revealed that the participants' EFL presentation skills developed after the implementation of computer mediated team based learning. In addition, their foreign language anxiety decreased. They became much more motivated and had the courage to express their own confidently without fearing from anything. The effectiveness of computer mediated team based learning may be due to the various activities, tasks and strategies the researcher presented to the students.

Using Facebook had a positive impact on the students' learning experience and motivation. Facebook was an innovative and effective tool in a student-centered learning environment that

\section{2}


enriched students' educational experiences, increased the relevance of the subject matter and encouraged students to collaborate effectively with their peers. From the perspective of the educator, the use of Facebook in a team-based pedagogy setting significantly enhanced the teaching and learning process as it allowed the educator to tap into the digital learning styles of the students and provided innovative ways of involving and motivating students in the learning process.

In addition, Twitter seemed to be a perfect tool to support learning English, especially in blended classrooms. Twitter was easily accessible from almost everywhere, so the students could practice at any time by sending and receiving messages either on the computer or the mobile phone. They could also decide how much time they spend reading and writing these messages. Also, Twitter was suitable for any level of English because in writing the messages, the students chose a topic and grammatical structure fitting their level. The use of Twitter as an online learning community helped to integrate students in the community who could not attend classroom.

Therefore, the significant differences found in favor of the post assessment of the EFL presentation skills and the pre assessment of the foreign language anxiety can be ascribed to the implementation of the team learning based on computer mediated communication. Thus, the program proved to be effective in developing EFL presentation skills and reducing foreign language anxiety among the participants of the study.

\section{Recommendations of the Study}

In the light of previous results, the following recommendations could be presented:

1. Teachers of English language should be trained on using Computer Mediated Team based Learning Program while teaching English to their students in different educational stages.

2. English language teacher should emphasize the development of the students' presentation skills in the early educational stages to develop them in the following stages.

\section{3}


3. Curriculum designers should make use of Computer Mediated Team based Learning when designing English language courses and overcoming foreign language anxiety.

\section{Suggestions for Further Research}

Based on the findings of the present research, the following implications for further research are suggested:-

1- Investigating the effectiveness of Computer Mediated Team based Learning in English language learning among secondary school students.

2- Clarifying the influence of Computer Mediated Team based Learning on other language skills such as writing and speaking.

3- Investigating the Computer Mediated Team based Learning in decreasing students' speaking anxiety.

4- Clarifying the effect of using other strategies on developing students' EFL presentation skills and reducing foreign language anxiety.

\section{References}

- Abderrezzag,S.(2009). The Effects of Anxiety On Students' Achievement The Case of Third Year LMD Students. University of Constantine Department of English. Unpublished master thesis , Mentouri University- Constantine, Algeria.

- Abidin,A.Z. \& Saleh, F. (2010). Soft Skills in the Development of Team-Based Electronic Learning Portfolio. Procedia Social and Behavioral Sciences 8, 626-633.

- Ahangari,S. Rassekh-Alqol,B. and Hamed,L.A. (2013). The Effect of Peer Assessment on Oral Presentation in an EFL Context. International Journal of Applied Linguistics \& English Literature,2(3),45-53.

- Akbari, M.\& Sadeghi, M. R.(2013). Foreign Language Learning Anxiety: The Case of Iranian Kurdish-Persian Bilinguals. International Research Journal of Applied and Basic Sciences,4(9), rOYO-YOIY. 
- Al-Shboul1, M. M.; Ahmad, I. S.; Nordin, M. S. and Abdul Rahman, Z. (2013). Foreign Language Anxiety and Achievement: Systematic Review. International Journal of English Linguistics,3(2),32-45.

- Andrade, M.\& Williams, K.(2009). Foreign Language Learning Anxiety in Japanese EFL University Classes: Physical, Emotional, Expressive, and Verbal Reactions. Sophia Junior College Faculty Journal,29,1-24.

- Arnaiz, P. \&Guillén, F.(2012). Foreign Language Anxiety in a Spanish University Setting: Interpersonal Differences. Revista de Psicodidáctica, 17(1), 5-26.

- Awan, R., Azher, M., Anwar, M. N., \& Amp; N. A. (2010). An Investigation of Foreign Language Classroom Anxiety and its Relationship with Students' Achievement. Journal of College Teaching and Learning, 7(11), 33-33-40.

- Ay, S. (2010). Young Adolescent Students' Foreign Language Anxiety in Relation to Language Skills at Different Levels. The Journal of International Social Research,3(11),83-91.

- Barker, A.(2010). Improve your Communication Skills. London: Kogan Page Limited.

- Borau1, K. ; Ullrich, C.; Feng1, J. and Shen, R.(2009). Microblogging for Language Learning: Using Twitter to Train Communicative and Cultural Competence. Springer-Verlag :Berlin Heidelberg.

- Chartrand, R.(2012). Social Networking for Language Learners: Creating Meaningful Output with Web 2.0 Tools. Knowledge Management \& E-Learning: An International Journal, 4(1),97-101.

- Csikosovaa, A., Senova, A. and Culkova, K.(2012). Improving of Communication and Presentation Skills of the University Students through E-learning. Procedia - Social and Behavioral Sciences 46 , $2847-2851$

- Cui, J. (2011). Research on High School Students' English Learning Anxiety. Journal of Language Teaching and Research, 2(4), 875880 .

- Diyyab, E. A. E. (2013).The Effectiveness of a Blended Learning Based Program in Developing EFL Speaking Skills and Reducing Anxiety among Faculty of Education Students. Unpublished master thesis, Benha University, Egypt.

\section{5}


- El-Sweedy, N. A. A. A. (2012). The Effects of a Suggested Program on Developing Beliefs and Teaching Skills Related to Writing among EFL Prospective Teachers. Unpublished doctoral dissertation, Faculty of Education, Benha University, Egypt.

- Emden, J. and Becker, L. (2004). Presentation Skills for Students. New York :Palgrave Macmillan.

- Erkaya, O. R. (2011). Teaching Oral Presentation Skills to College EFL Students. Humanising language Teaching, 13(1),1-7.

- Greza , D. and Berings, V. (2010). Peer Assessment of Oral Presentation Skills. Procedia Social and Behavioral Sciences 2, 1776-1780.

- Inuwa, I. M; Al-rawahy, M ; Roychoudhry, S and TaranikantI, V. (2012). Implementing a Modified Team-based Learning Strategy in the First Phase of an Outcome-based Curriculum - Challenges and Prospects. Teacher, 34: e492-e499.

- Khodadady, E. \& Khajavy, G. H. (2013) Exploring the Role of Anxiety and Motivation in Foreign Language Achievement: A Structural Equation Modeling Approach. Porta Linguarum 20,269286

- King, J. (2002). Preparing EFL Learners for Oral Presentations. Journal of Humanistic Studies, 4, 401-418

- LeMond, M. M.(2004). Synchronous Computer-Mediated TeamBased Learning in the Spanish Foreign Language Classroom. Unpublished doctoral dissertation, The University of Texas at Austin. U.S.A.

- Lian, H. L. \& Budin, M. B. (2014). Investigating the Relationship between English Language Anxiety and the Achievement of Schoolbased Oral English Test among Malaysian Form Four Students. International Journal of Learning, Teaching and Educational Research , 2(1),. 67-79.

- MacAnthony, D. \& McCrohan, G. (2000). A Pedagogical Justification for Teaching Presentation Skills in English Language Classes. Available online at: www.kagawa-u.ac.jp/highedu/journal10_14.pdf. Retrieved on (16/7/2014).

- MacIntyre, P. D. (1999) cited in Ay, S. (2010). Young Adolescent Students' Foreign Language Anxiety in Relation to Language Skills at Different Levels. The Journal of International Social Research,3(11),83-91.

\section{6}


- Mandel, S.(2000). Effective Presentation Skills: A Practical Guide to Better Speaking. Boston:A fifty minute, series book.

- Mazdayasna, G. (2012). Objective Assessment of Oral Presentations and EFL Learners' Speaking Development. Sheikhbahaee EFL Journal ,1(1),23-38.

- Michaelsen, L. K.\& Sweet, M.(2008). The Essential Elements of Team-Based Learning. New Directions for Teaching and Learning, 116,7-27.

- Michaelsen, L. K.(2008). Getting Started with Team Learning. Available online at: https://www.med.illinois.edu/.../Michaelson.pdf.Retrieved on $8 / 7 / 2014$

- Occhipinti, A.(2009). Foreign Language Anxiety in in-Class Speaking Activities :Two Learning Contexts in Comparison. Unpublished master thesis, The University of Oslo.

- Otoshi, J. \& Heffernan, N. (2008). Factors Predicting Effective Oral Presentations in EFL Classrooms. Asian EFL Journal, 10(1), 65-78.

- Partridge, L. (2007).Teams: Learning Made Simple. London: Butterworth-Heinemann.

- Rasiah, R.R.V.(2014). Transformative Higher Education Teaching and Learning: Using Social Media in a Team-Based Learning Environment. Procedia - Social and Behavioral Sciences 123 , $369-379$.

- Reid-Hector, J. (2006). Inquiry-Based Learning Practices and Team Learning: A Model for Experienced Based Adult Learning. Unpublished doctoral dissertation, Columbia University.

- Shokri, N.M.(2010).Team Project Facilitates Language Learning. Procedia Social and Behavioral Sciences 7(C), 555-564

- Suwa, T.; Miyahara, K. and Ishimatsu, J.(2012). Improvement Techniques for Foreign Language Technical Presentation Skills Used in Undergraduate Experiment Course. IERI Procedia 1,160165

- Tóth, Zs. (2007). Predictors of Foreign-language Anxiety: Examining the Relationship between Anxiety and other Individual Learner Variables. In J. Horváth \& M. Nikolov (Eds.).Empirical Studies in English Applied Linguistics (pp. 123-148). Pécs: Lingua Franca Csoport. 
- $\quad$ Trang, T.T.T. Moni, K. and Baldauf, R.B. (2012). Foreign Language Anxiety and its Effects on Students' Determination to Study English: To Abandon or not to Abandon? TESOL in Context, S3.114.

- Tsai, C.C.(2013). The Impact of Foreign Language Anxiety, Test Anxiety, and Self-efficacy among Senior High School Students in Taiwan. International Journal of English Language and Linguistics Research,1(3),1-17.

- Williams, K.E. \&Andrade, M.R.(2008). Foreign Language Learning Anxiety in Japanese EFL University Classes: Causes, Coping, and Locus of Control. Electronic Journal of Foreign Language Teaching ,5(2),181-191.

- Zheng, Y.(2008). Anxiety and Second/ Foreign Language Learning Revisited. Canadian Journal for New Scholars in Education,1(1),112. 